\title{
Mark-recapture estimates suggest declines in abundance of common bottlenose dolphin stocks in the main Hawaiian Islands
}

\author{
Amy M. Van Cise ${ }^{1, *}$, Robin W. Baird ${ }^{1}$, Annette E. Harnish ${ }^{1}$, Jens J. Currie ${ }^{2}$, \\ Stephanie H. Stack ${ }^{2}$, Tori Cullins ${ }^{3}$, Antoinette M. Gorgone ${ }^{1}$ \\ ${ }^{1}$ Cascadia Research Collective, 218 1/2 W 4th Ave., Olympia, WA 98501, USA \\ ${ }^{2}$ Pacific Whale Foundation, Wailuku, 300 Ma'alaea Road, Suite 211, HI 96793, USA \\ ${ }^{3}$ Wild Dolphin Foundation, Wai'anae, 87-1002C Hakimo Pl, HI 96792, USA
}

\begin{abstract}
Species conservation relies on understanding population demographics, yet this information is lacking for many species and populations. Four stocks of common bottlenose dolphins Tursiops truncatus inhabiting the waters surrounding the main Hawaiian Islands (USA) are exposed to anthropogenic disturbances including fisheries interactions, tourism, naval activities, ocean noise, and contaminants. Although these stocks are managed under the Marine Mammal Protection Act, a demographic assessment has not been undertaken since 2006, and there is currently no information on population trends. We combined regular survey effort with citizen science contributions to estimate apparent survival and annual abundance within each stock using photographs collected between 2000 and 2018. Over this time period, we collected 2818 highquality identifications of 765 distinctive individuals across all 4 stocks. Analyses of inter-annual movements indicated that individuals exhibit restricted habitat use within stocks, which contributed to non-random sampling. Annual abundance estimates ranged from the 10 s to the low 100s. Apparent survival ranged from 0.84 to 0.9, with lower-than-expected estimates in all stocks. Annual abundance estimates declined in 3 of the 4 stocks; however, this decline was not significant for the Kaua'i/Ni'ihau and O'ahu stocks, and may be an artifact of sampling design in all stocks. Given the small population size for these stocks, it is important to closely monitor trends in abundance as a first step in mitigating negative effects of anthropogenic activities. Future efforts should focus on consistent geographic coverage in all stocks to decrease model uncertainty and improve trend assessment.
\end{abstract}

KEY WORDS: Demographics - Bottlenose dolphin - Tursiops truncatus $\cdot$ Abundance $\cdot$ Survival Mark-recapture $\cdot$ Conservation $\cdot$ Management

\section{INTRODUCTION}

Modern strategies for the conservation and management of species rely primarily on the knowledge of population demographics, such as abundance, recruitment, survival, migration, and trends in these over time. In addition to forming the basis of regional

\footnotetext{
${ }^{*}$ Corresponding author: avancise@gmail.com
}

and national management plans, these parameters are important criteria in the IUCN determination of extinction risk, which are periodically reviewed and rely on available data (Wells et al. 2019). Population demographic patterns are known to vary within species, including at the level of stocks or demographically independent populations, and are influenced

() The authors 2021. Open Access under Creative Commons by Attribution Licence. Use, distribution and reproduction are unrestricted. Authors and original publication must be credited. 
by the local environment, interactions with humans, and behaviors such as movement patterns and degree of site fidelity (Lebreton et al. 1992, Switzer 1993). It is especially important to monitor these trends in species or populations that regularly come in contact with anthropogenic stressors, in order to understand whether those stressors threaten the population or species.

In the USA, population demographics of most cetaceans are assessed by the National Marine Fisheries Service (NMFS) using observational line-transect surveys conducted from a variety of platforms (e.g. Bradford et al. 2017). However, these surveys are decreasing in frequency, and do not always capture nearshore populations sufficiently to permit abundance estimation for the entire population. In these cases, mark-recapture methods that use natural scars and coloration patterns to identify individuals can be an effective way to estimate trends in population abundance, recruitment, and apparent survival, including both death and emigration (e.g. Conn et al. 2011, Rosel et al. 2011, Haughey et al. 2020). Markrecapture surveys can be conducted from small vessels nearshore, and thus are often an effective highresolution tool to assess the demographics of neritic populations.

Common bottlenose dolphins Tursiops truncatus (or bottlenose dolphins) are globally distributed in tropical and warm-temperate waters. They are commonly found in nearshore waters, but are known to form offshore populations in some regions (e.g. Silva et al. 2009, Conn et al. 2011, Rosel et al. 2011), which will occasionally visit nearshore habitats. Studies of coastal populations of bottlenose dolphins indicate a wide range of distributional behaviors, including seasonal migrations, periodic residency, and longrange movements (Wells \& Scott 2018). They live in fission-fusion societies, regularly forming small groups whose composition can be determined by a combination of sex, age, reproductive condition, familial relations, affiliation histories, and foraging habits. These smaller groups will sometimes join to form groups of more than 100, occasionally exceeding 1000 (Connor et al. 2001, Rogers et al. 2004, Louis et al. 2018). They are social learners and are known to transfer behaviors such as feeding techniques, vocal behavior, and play behaviors (e.g. Reiss \& McCowan 1993, McCowan et al. 2000, Krützen et al. 2005, 2014, Sargeant et al. 2005). In some populations, social groups have distinct ecological niches (Louis et al. 2018); this strategy of resource partitioning is thought to reduce competition and allow for larger local populations.
Although bottlenose dolphins are among the most common delphinids, and are classified by the IUCN as a species of Least Concern, they are also listed as having an unknown population trend. Moreover, they are locally data deficient with respect to abundance and distribution (Wells et al. 2019). Within many local populations, abundance estimates are hampered by large, unknown, and/or poorly defined distributional ranges, and insufficient genetic data to determine subpopulation structure and patterns of residency or habitat use (e.g. Forcada et al. 2004). As a coastally distributed species, bottlenose dolphins face a number of natural and anthropogenic threats that may negatively affect survival and abundance, including fisheries interactions (Morteo et al. 2012, Baird 2016), disturbance from tour vessels (Bejder et al. 2006), vessel strikes (Dwyer et al. 2014), contaminants (Wells et al. 2004, Reif et al. 2006), harmful algal blooms (Twiner et al. 2012), habitat loss and degradation (Karczmarski et al. 2017), oceanic noise disturbance (Buckstaff 2004), and cumulative impacts (Maxwell et al. 2013), although in some specialized cases human interactions can have a positive effect on population demographics (Bezamat et al. 2019).

In the main Hawaiian Islands, bottlenose dolphins form 4 island-associated stocks with high site fidelity and little mixing among them (Baird et al. 2009, Martien et al. 2011, Baird 2016). Bottlenose dolphins inhabiting the deeper waters surrounding the islands are likely part of a broadly distributed pelagic population (Martien et al. 2012, Carretta et al. 2019) that will occasionally visit the shallower waters surrounding the islands. These stocks are managed by NMFS, as mandated by the Marine Mammal Protection Act (MMPA; 50 CFR 216) in order to assess the impact of anthropogenic activities on population demographics. As part of the photo-identification (ID) study of Baird et al. (2009), abundance of marked animals was estimated using the Lincoln-Petersen estimator (Seber 1982) applied to mark-recapture data for each of the 4 stocks between 2000 and 2006. Based on that paper, stock estimates were 184 for the Kaua'i/Ni'ihau stock, 743 for O'ahu, 91 for Maui Nui, and 128 for Hawai'i (Carretta et al. 2019). However, NOAA considers these estimates outdated for the purposes of stock management, and to date no assessment has been made of population trends over time. Here, we estimated abundance and apparent survival (affected by both death and emigration) of each stock within the resident population using photoID mark-recapture models, and assessed trends in abundance between 2000 and 2018 . 


\section{MATERIALS AND METHODS}

\subsection{Data collection}

Dorsal photographs were collected around the main Hawaiian Islands between 2000 and 2018 from both systematic surveys by Cascadia Research Collective (CRC) (Baird et al. 2013) and the Pacific Whale Foundation (PWF), as well as opportunistic sightings from other researchers and citizen scientists, totaling 601 days with bottlenose dolphin encounters over the $19 \mathrm{yr}$ period. For the purpose of this study, an encounter is defined as an observation of 1 or more individual bottlenose dolphins in a group, during which time photographs are taken of as many individuals as possible. A single day may include 1 or more encounters with bottlenose dolphins. Photographs used in an earlier study (Baird et al. 2009) were incorporated into the sample. All photographs, regardless of source, were processed as described by Baird et al. (2009). An expert initially examined photos from each encounter, grouping photos by individual. For each sighting of each individual, the best photo was scored for the quality of the photograph and distinctiveness of the individual. Scores were 1-4 for both categories with 4 representing the highest quality and distinctiveness. Once all individuals in an encounter were identified, those individuals were compared to the rest of the dataset to search for a match. Matches were confirmed by a second observer, and unmatched individuals were once again compared with the dataset by a second observer to confirm no match.

\subsection{Data quality control}

Prior to data analysis, the dataset of identified individuals was adjusted as follows:

(1) Individuals were removed if their distinctiveness score was less than 3 .

(2) Individual sightings were removed if the highest photo quality was less than 3 .

(3) Individuals identified as belonging to a nonresident stock (see Section 2.4) were removed.

(4) Individual sightings were removed if they came from encounters that had not been completely processed $(n=17)$, given that incomplete encounters (i.e. encounters where not all photographs have been processed) could bias the results. This resulted in removal of 41 individual sightings.

(5) Sightings from the windward side of Hawai'i Island were removed from this study, because inconsistent sampling in that region over the study period is likely to bias the results.

\subsection{Testing dataset biases}

In order to test the assumption that individuals were sampled at random within a stock, we compared the frequency of individual re-sights to that expected from a randomly sampled stock. We generated simulated sighting datasets for each stock following the approach outlined by Kery \& Schaub (2012), given the number of sampling occasions and average number of new individuals encountered on each sampling occasion for each stock, using an annual apparent survival of 0.9 (e.g. Stolen \& Barlow 2003) and annual re-sighting probability of 0.4 (Kery $\&$ Schaub 2012) for all stocks. We then counted the number of times each individual was sighted over the study period in both the simulated and real datasets, and tested for statistical differentiation in sighting rate between the simulated and real datasets using a 2-sample Wilcoxon rank sum (Mann-Whitney) test.

We further tested for patterns of spatio-temporal variability in individual habitat use within stocks that might lead to sampling bias in the dataset. Because some citizen scientist contributions do not have associated location data, these were excluded from this test. To estimate average individual inter-annual travel distance, we randomly selected 1 location per individual per year, calculated the distance between locations, and took the mean across all individuals and all years. To estimate the expected inter-annual travel distance for a randomly mixed population, we randomly selected $x$ individual locations from all available locations per year, where $x=$ the number of actual individual sightings in each year, and again calculated the mean distance across all individuals and years. We then compared the true inter-annual distance to the expected inter-annual travel distance in a randomly mixing population using a 1-sided Wilcoxon rank sum test.

\subsection{Demographic model setup and abundance estimation}

In order to optimize the utility of the available data, the selected abundance estimation method reflects a compromise between spatially explicit models and more traditional mark-recapture models, which do not typically account for spatio-temporal heterogeneity in individual location or experimental design. We used a POPAN model (Schwarz \& Arnason 1996), stratified within each stock according to gaps in observations or significant bathymetric/geographic changes that affect how protected nearshore habitat 
is. Individuals were assigned to a subarea stratum based on their first sighting location; individual capture histories included all subsequent sightings of the individual regardless of observation location. Because subarea stratification requires knowledge of an individual's location, individuals that had no associated GPS data across all encounters were excluded from POPAN analyses.

Population abundance analyses roughly follow Bradford et al. (2018). Estimation was undertaken using the 'RMark/MARK' package (White \& Burnham 1999, Laake 2014) in R v3.6.1 (R Core Team 2016), using the POPAN implementation of a Jolly-Seber model (Jolly 1965, Seber 1965), which estimates the abundance of a hypothetical super-population that includes all individuals that ever enter into the population. We used year as the sampling period and ignored re-sightings within each year. Because sampling effort varied among years and stocks, abundance estimates were only attempted for each stock in the years when that stock was sampled. POPAN estimates 4 parameters: apparent survival $(\phi)$, capture probability (p), probability of entry into the population $(\beta)$, and super-population size $(N)$. We used a logit link function to model $\phi$ and $\mathrm{p}$, a multinomial logit link function to model $\beta$, and the log link function to model $N$.

The POPAN model assumes (1) unique, permanent, and correctly identified markings on all distinctive individuals, (2) homogeneous apparent survival probability, (3) homogeneous capture probability, (4) independent probability of capture and apparent survival, (5) instantaneous sampling, and (6) constant sample area. The first 2 assumptions are met by the data in this study. To meet the first assumption, we use only good- and excellent-quality photos (photo quality score 3-4) and distinctive and very distinctive individuals (individual distinctiveness 3-4) in the models. The third assumption, that of homogeneous capture probability, is likely true with respect to marked vs. unmarked individuals. The additional spatio-temporal variability in capture probability, driven by ecological and individual differences in habitat use within each stock, was addressed by subdividing stocks into subareas and estimating capture probability and probability of entry into the stock within each subarea. The fourth assumption, independent probability of capture and apparent survival, could be violated by social associations among individuals or by learned habitat preferences. This assumption is also partially addressed by subdividing stocks to control for geographic bias in sampling. The fifth and sixth assumptions were violated by weather and logistical constraints to sampling, which caused sampling effort to vary spatially and in duration each year. In order to minimize variability in sampling effort, we used one year as the sampling period. This violates the assumption of instantaneous sampling, but the violation can be addressed by allowing capture probability to vary with time (O'Brien et al. 2005).

For resident populations of bottlenose dolphins, an additional source of potential bias in abundance estimates comes from visits from non-resident individuals, which may artificially inflate the estimated abundance of the resident population (Pradel et al. 1997, Rosel et al. 2011). In this study, we rely on a long-term dataset with multiple samples per year to improve our ability to identify resident vs. non-resident individuals, based on assessment of factors such as location (based on depth) at which the animals were encountered, animal size, and social connectivity with the resident population. We exclude groups from the analyses thought to be part of the offshore population based on these factors, and discuss results from social network analyses relevant to the likelihood of additional non-resident individuals being included in the sample.

For each stock, model-estimated $\mathrm{p}$ and $\beta$ were allowed to either be constant or vary by year, subarea, or subarea $\times$ year. $N$ was set to vary by subarea. $\phi$ was held constant in each stock, as published estimates for apparent survival in bottlenose dolphin populations indicate that this parameter is not likely to vary across years (Carretta et al. 2016). This resulted in 16 different models tested within each stock. The optimal model was selected by minimizing Akaike's information criterion corrected for small sample size $\left(\mathrm{AIC}_{\mathrm{c}}\right.$ ) (Hurvich \& Tsai 1989, Akaike 1998). Model goodness-of-fit was estimated using RELEASE (Burnham 1987) to estimate a variance inflation factor $(\hat{c})$. For each stock, $\hat{c}>1$ indicated overdispersion in that stock, which was corrected for before model selection and parameter estimation by computing quasi-AIC ${ }_{\mathrm{c}}\left(\mathrm{QAIC}_{\mathrm{c}}\right)$ (Anderson et al. 1994) and multiplying all variance estimates by $\hat{c}$.

Parameter estimates were averaged across all models proportional to their $\mathrm{AIC}_{\mathrm{c}}$ weight to account for model uncertainty. Model-averaged annual abundances $\left(N_{i}, i=2000,2001,2002 \ldots, 2018\right)$, standard error (SE), and $95 \%$ confidence interval (CI) for each stock around the main Hawaiian Islands were estimated using 'popan.derived' in RMark.

We corrected estimates of $N_{i}$ and $95 \%$ CI for the stock-specific proportion of distinctive individuals in 
each stock $(\theta)$ based on the mean proportion of distinctive individuals in each encounter. We first tested for annual and stock-specific differences in the proportion of high quality photos taken and in $\theta$ using an ANOVA in R, and plotted residuals to confirm that the data fit ANOVA assumptions of normality and heterogeneity of variance (results not shown). Following this, within each stock we calculated $\theta=n_{\text {dist3,4 }} / n_{\text {total }}$ where $n_{\text {dist } 3,4}$ is the number of distinctive or very distinctive individuals documented during an encounter, and $n_{\text {total }}$ is the total number of individuals documented during an encounter. Both $n_{\text {dist3,4 }}$ and $n_{\text {total }}$ were calculated using only the best quality photos (photo quality of 3 or 4 ). We restricted this analysis to include only encounters with groups of 4 or more documented individuals, so that the proportion would not be biased by small group sizes (Bradford et al. 2018). For estimates of stock-specific $\theta$, we used only the subset of the data that was collected by CRC, because standard CRC field protocol is to photograph all individuals regardless of size or distinctiveness to minimize bias in individual documentation. The final, corrected abundance estimate for each population each year is

$$
N_{i j, \text { corr }}=\frac{N_{i j}}{\theta_{j}}
$$

for each stock $j$ in the study. Variance around $N_{i}$ was estimated using the delta method from Seber (1982), as described by Bradford et al. (2018), and used to estimate confidence intervals following Burnham (1987).

\subsection{Estimating confidence in population trends}

Finally, we tested the trends estimated in this study by randomly generating annual abundances from multivariate normal distributions with means and covariance matrices derived from the POPAN estimates and covariance matrices for annual abundance within each stock, and fitting a linear regression to the randomly generated abundance estimates. This was repeated 10000 times, and we used the distribution of regression slopes for each stock to calculate the $95 \%$ confidence intervals of population trends for each stock.

This process was repeated for all stocks combined, using only years in which an estimate was made for all stocks ( $\mathrm{n}=12$ years), in order to understand the trajectory of abundance trends at a metapopulation level for stocks in the main Hawaiian Islands.

\subsection{Code availability}

All codes for analyses and manuscript generation were written using R and R Markdown, and are available on GitHub at https://github.com/cascadiaresearch/ HITt_abundance or https://github.com/avancise/HITt _abundance.

\section{RESULTS}

During the entire study period, 1413 individuals were identified across all 4 stocks in the main Hawaiian Islands, for a total of 5220 individual sightings. Twenty-eight individuals were determined to be from an offshore population and were removed. Eight of these were identified on a single encounter off Hawai'i Island, in water $>3000 \mathrm{~m}$ deep, were observably larger than residents of the Hawaiian population, and had no social connection with any Hawaiian stocks (Baird 2016, Cascadia Research Collective unpublished data). An additional 19 were observed around Kaula Rock, offshore of Ni'ihau and outside the boundaries for any of the stocks. The final individual was identified during a NOAA offshore survey. Additionally, 26 individuals that were encountered during a NOAA survey of the windward side of Hawai'i Island were removed due to inconsistent sampling of this region. Once preliminary quality control filtering was completed, the final dataset comprised 2818 observations of 765 individuals, with a median of 2 observations per individual.

However, 355 of the individuals in the dataset were observed on only a single occasion. In 3 of the 4 stocks, sampling differed significantly from random (Fig. 1). Further, our test of individual inter-annual travel distance indicated that, in all stocks, individuals occupy a significantly smaller portion of the available habitat than expected (Fig. 2). Because sampling effort varied spatially within each stock, this variability in habitat use is likely a cause of the nonrandom sampling pattern detected in the dataset.

Non-random sampling was partially accounted for by subdividing stocks spatially (Fig. 3A); annual abundance estimates in each subarea are based only on years with observations in that subarea. Subdividing stocks resulted in 2 to 4 subareas within each stock. Five individuals were never associated with a GPS location throughout the study period and therefore could not be assigned a subarea and were removed from POPAN abundance estimates. Individuals with known locations were re-sighted in the same subarea as their original sighting during $76 \%$ 

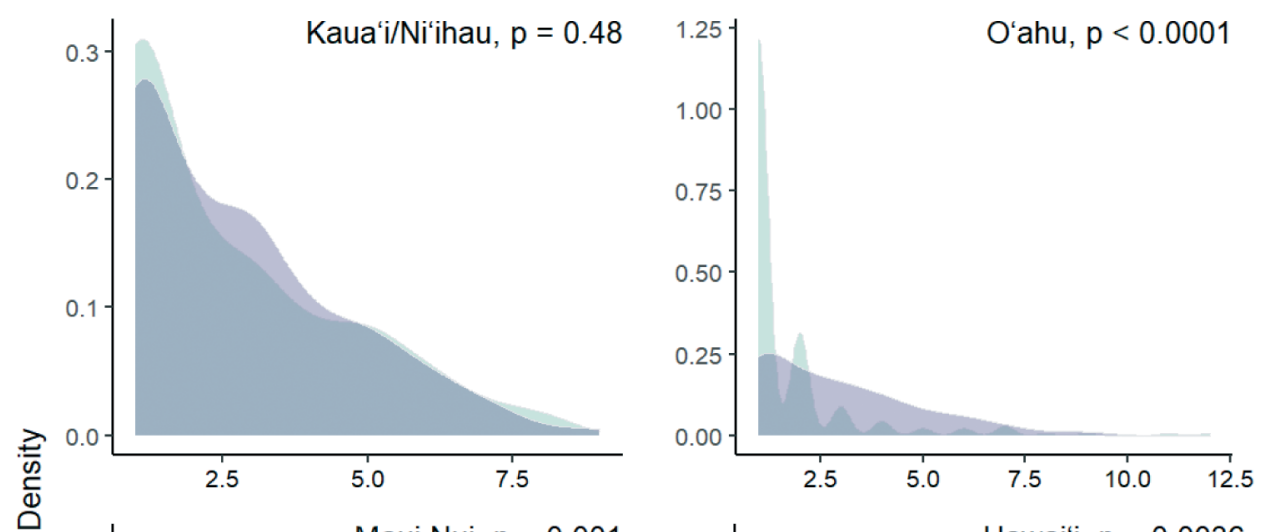

Real data
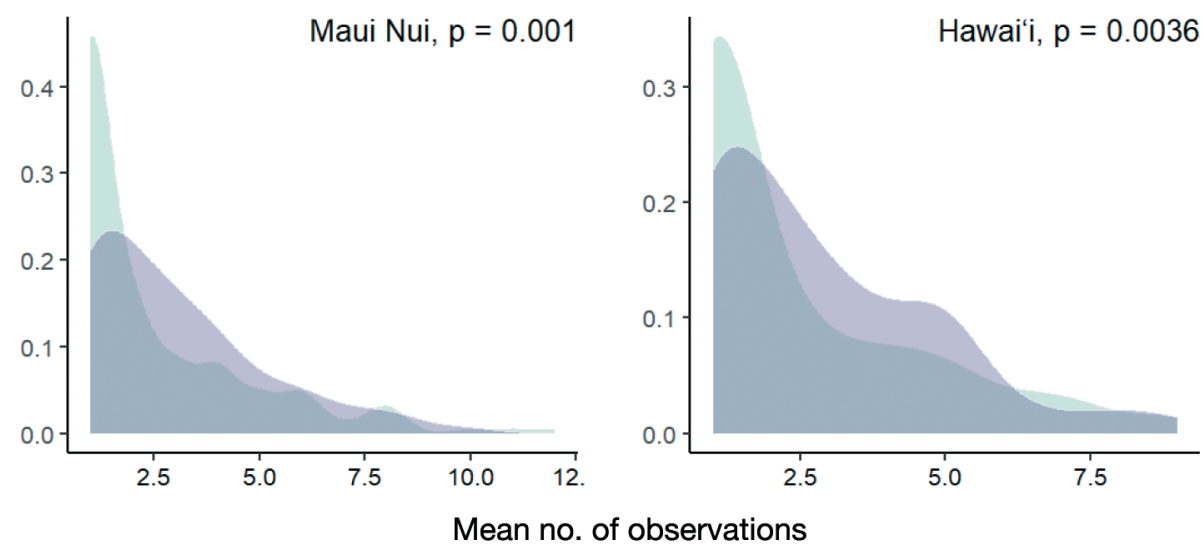

Simulated data

Mean no. of observations

Fig. 1. Within-stock comparisons of the Hawaiian bottlenose common dolphin dataset used in this study with a simulated randomly sampled dataset. All p-values displayed are the probability that the 2 distributions are the same, from a 2-sample Wilcoxon rank sum test

of re-sights. A small number of individuals $(\mathrm{n}=9)$ were encountered in both Maui Nui and $\mathrm{O}^{\prime} \mathrm{ahu}$ (Table 1); these individual encounters were incorporated into the estimate for the stock where they were first observed. The number of encounters in the curated dataset differed considerably by stock and subarea over the study period (Table 1, Fig. S1 in the Supplement at www.int-res.com/articles/suppl/n045 p037_supp.pdf). Stratifying by subareas within stocks revealed subareas where sampling deviated from random, including 1 subarea in Maui Nui and both subareas in Hawai'i and O'ahu (Fig. 3B).

Discovery curves approached an asymptote in Kaua'i/Ni'ihau, O'ahu, and Maui Nui, suggesting that a large portion of the population was sampled over the cumulative sampling period (Fig. 4A). In Hawai'i, the discovery curve still approximated 1:1 due to multiple large influxes of individuals late in the study period. This includes 29 new individuals that were added in 2012 resulting in a large jump in the discovery curve, 19 of which were seen at least once in later years. Subdividing stocks revealed subareas within each stock that have been sampled fewer times and thus are not as close to reaching an asymptote, including 2 subareas in Kaua'i/Ni'ihau and 1 each in Maui Nui, Hawai'i, and O'ahu (Fig. 4B). Goodness-of-fit testing indicated overdispersion of the data with respect to the model in all stocks (Table 2), and model fit was adjusted by $\hat{c}$.

Of the 16 models tested within each stock, the optimal model allowed capture probability to vary by year and subarea in Kaua'i/Ni'ihau and Maui Nui, with $\geq 99 \%$ of the QAIC $_{\mathrm{C}}$ weight for these stocks (Table 2). Capture probability varied by time only in the optimal model for O'ahu, with $76 \%$ of the model weight, and Hawai'i, with $99 \%$ of the model weight. Probability of entry varied by subarea in the optimal model for all stocks.

Model-averaged capture probability varied widely among years and subareas, averaging 0.23 (95\% CI: $2.4 \times 10^{-5}$ to 0.78$)$ in Maui Nui, 0.22 (95\% CI: 0.007-0.67) in O'ahu, 0.42 (95\% CI: 0.079-0.99) in Hawai'i, and 0.35 (95\% CI: $1.3 \times 10^{-5}$ to 1$)$ in Kaua'i/Ni'ihau (Table S1). Apparent survival ( $\phi$ ) estimates ranged from 0.84 to 0.9 (Table 3), with the highest apparent survival in Kaua'i/Ni'ihau and lowest apparent survival in O'ahu. 


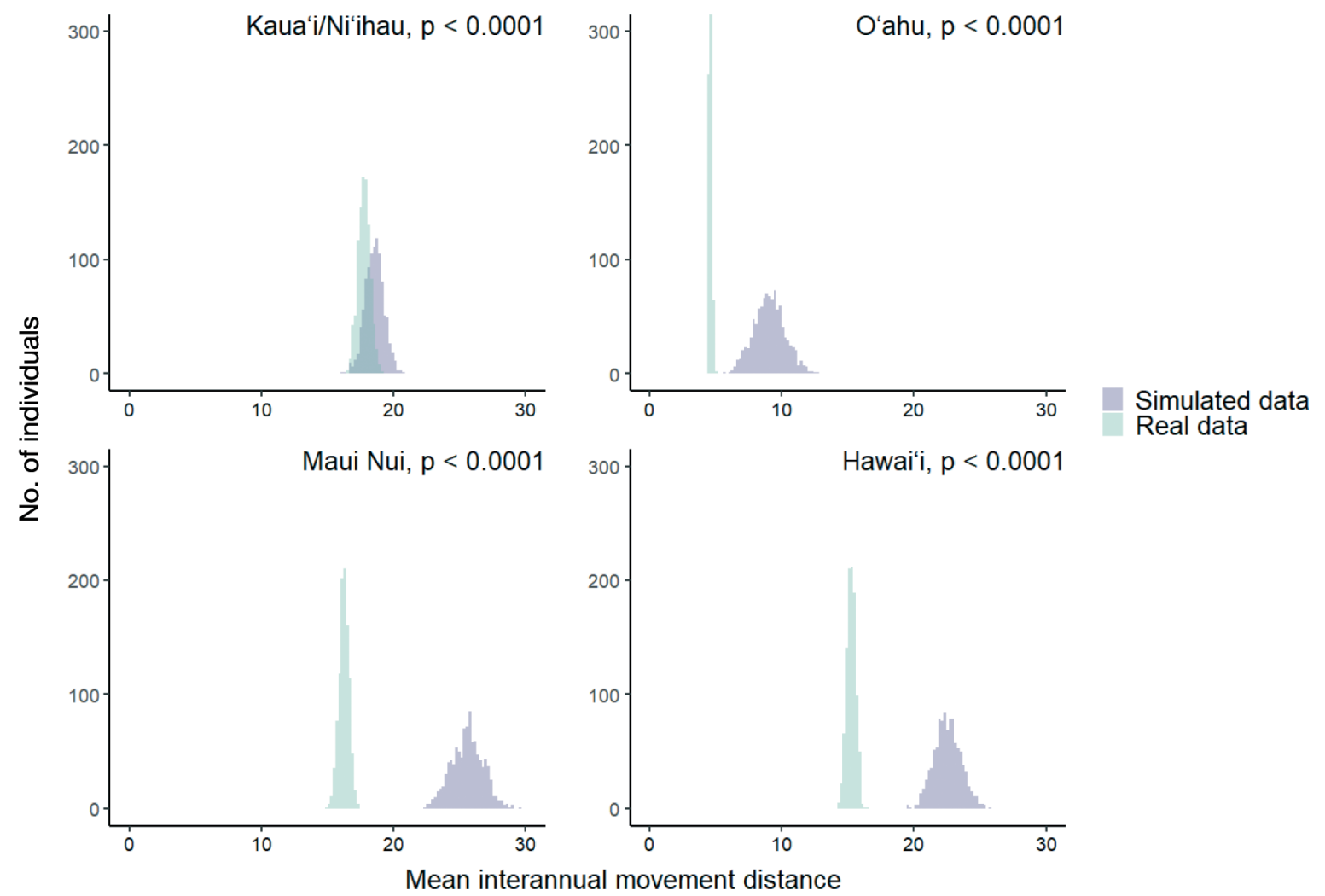

Fig. 2. Estimates of individual inter-annual movement distance compared with expected interannual movements of individuals in a randomly mixing stock of Hawaiian bottlenose common dolphin. All p-values are the likelihood that the real distance traveled is not smaller than the simulated distance traveled, from a 1-sided Wilcoxon rank sum test

The proportion of individuals with high-quality photos (quality $\geq 3$, mean $94 \%$ of total photos in an encounter), calculated using only the subset of the data collected by CRC, did not vary significantly across years (ANOVA $F_{1}=0.003, \mathrm{p}=0.96$ ), but did vary by stock (ANOVA $F_{3}=5.1, \mathrm{p}=0.003$ ). The proportion of distinctive animals in an encounter, calculated using the same subset of data collected by CRC, did vary across years (ANOVA $F_{1}=8.1, \mathrm{p}=$ 0.005 ) as well as among stocks (ANOVA $F_{3}=3.446$, $\mathrm{p}=0.02$ ). Values for mean and variation in the proportion of distinctive individuals across encounters $(\theta)$ used to adjust abundance estimates and confidence intervals are reported in Table 4.

Abundance estimates indicate annual growth rates of $10.5,-2.6,-8.6$, and $-3 \%$, respectively in Hawai'i, Kaua'i/Ni'ihau, Maui Nui, and O'ahu (Table 5, Fig. 5). Because confidence intervals are wide for all stocks, actual growth rates may be smaller or larger. 95\% CIs for the slope of population trends in each stock were 0.94 to $5.31,-6.9$ to $-1.7,-13$ to -6 , and -10.3 to 2.7 in Hawai'i, Kaua'i/Ni'ihau, Maui Nui, and O'ahu, respectively. When the main Hawaiian Island population trend is considered, for years in which abun- dance estimates were calculated in all stocks, the $95 \%$ CI for the slope of population growth was -19.3 to -4.8 .

\section{DISCUSSION}

\subsection{Bottlenose dolphin stocks around the main Hawaiian Islands appear to be declining}

Our results indicate lower-than-expected apparent survival rates in all stocks of bottlenose dolphins in the main Hawaiian Islands (Carretta et al. 2016). Point estimates indicate a negative trend in abundance in 3 of the 4 stocks, and $95 \%$ CIs for the slopes of the trends are consistent with a decline in abundance for 2 of the stocks. Abundance estimates for the Hawai'i stock, representing the leeward side of the island, increased over the study period. Although these abundance estimates and trends represent the best available data, they should be interpreted with caution as the results may be driven by biases in study design, which are discussed in Section 4.2 . 


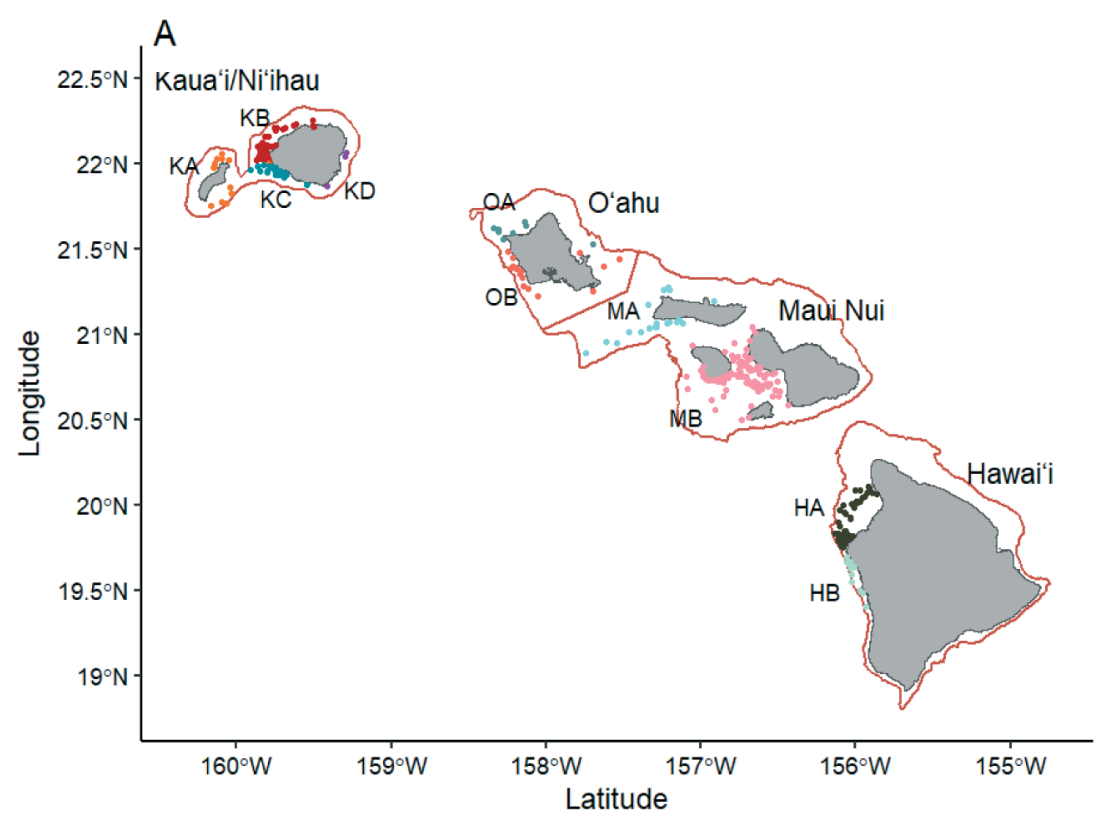

B
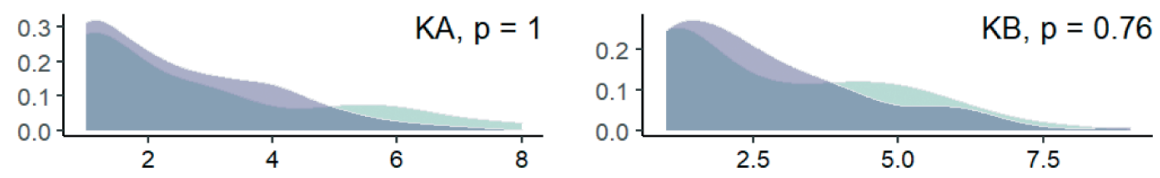

Real data Simulated data
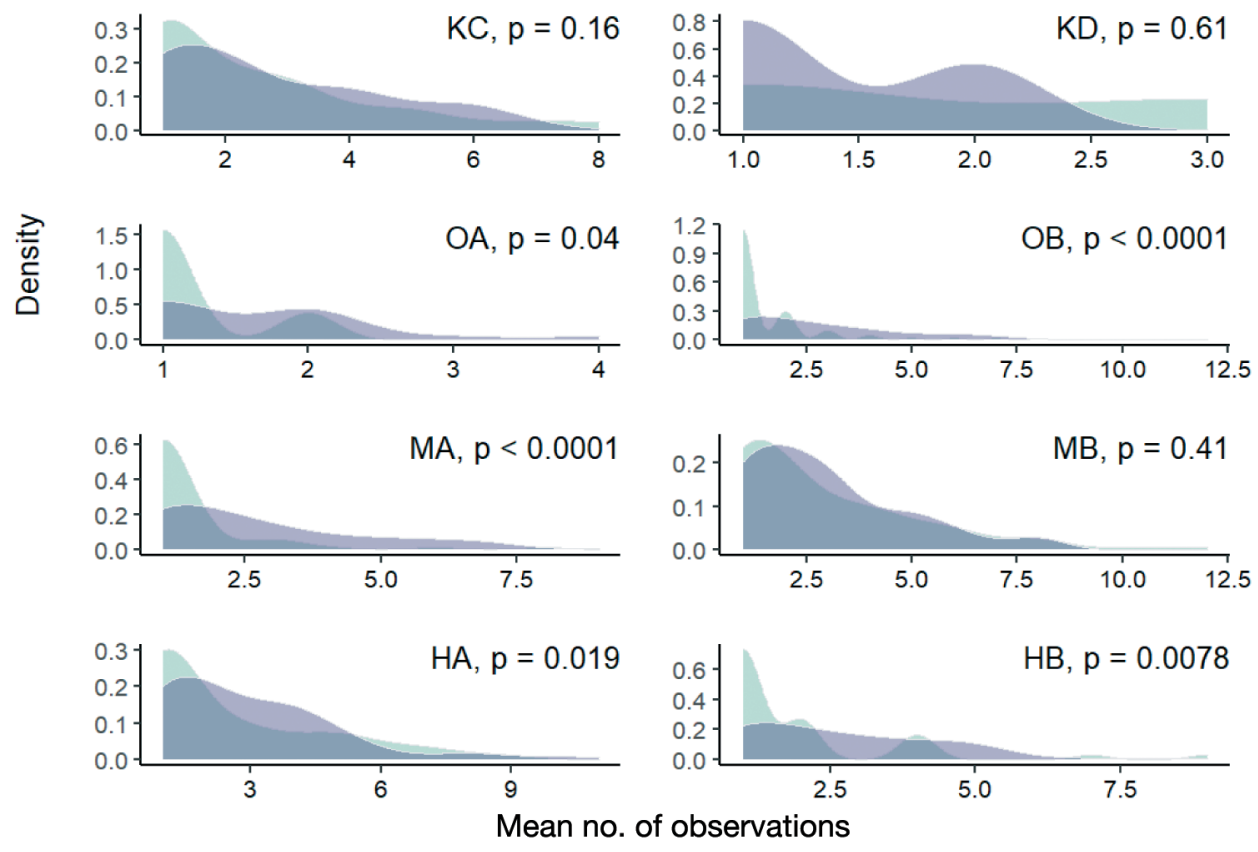

Fig. 3. (A) Sighting locations and subarea stratification of individual Hawaiian bottlenose common dolphins in this study. Individuals were assigned to a subarea based on the location where they were first sighted. Subareas were defined by assessing natural breaks in the stock, or by using shifts in geography or aspect of land that would affect how protected nearshore habitat is. Red lines indicate stock boundaries; colored dots correspond to the subarea colors in Fig. 4B. (B) Within-subarea comparison of the dataset used in this study with a simulated randomly sampled dataset. All p-values displayed are the probability that the 2 distributions are the same, from a 2-sample Wilcoxon rank sum test. Subarea designations in both subplots are as follows: Kaua'i/Ni'ihau: KA, KB, KC, KD; O'ahu: OA, OB; Maui Nui: MA, MB; Hawai'i: HA, HB 
Table 1. Number of encounters by subarea (see Fig. 3 for locations) within each Hawaiian common bottlenose dolphin stock, number of individuals identified in each subarea, and the range of years of coverage in each subarea. Individuals were assigned a subarea based on their first sighting location; a small number of individuals were observed in both Maui Nui and O'ahu. CRC: Cascadia Research Collective; PWF: Pacific Whale Foundation; other: citizen scientist contributions

\begin{tabular}{|c|c|c|c|c|c|c|c|}
\hline Stock & Subarea & Span of years & $\begin{array}{c}\text { No. of } \\
\text { individuals }\end{array}$ & $\begin{array}{c}\text { CRC } \\
\text { encounters }\end{array}$ & $\begin{array}{c}\text { PWF } \\
\text { encounters }\end{array}$ & $\begin{array}{c}\text { Other } \\
\text { encounters }\end{array}$ & $\begin{array}{c}\text { Total } \\
\text { encounters }\end{array}$ \\
\hline Kaua'i/Ni'ihau & $\mathrm{KA}$ & 2003-2018 & 36 & 35 & 0 & 6 & 41 \\
\hline Kaua'i/Ni'ihau & $\mathrm{KB}$ & $2003-2018$ & 80 & 39 & 0 & 9 & 48 \\
\hline Kaua'i/Ni'ihau & $\mathrm{KC}$ & $2004-2017$ & 71 & 26 & 0 & 11 & 37 \\
\hline Kaua'i/Ni'ihau & $\mathrm{KD}$ & $2003-2015$ & 5 & 5 & 0 & 0 & 5 \\
\hline $\mathrm{O}^{\prime} \mathrm{ahu}$ & $\mathrm{MB}$ & $2007-2008$ & 6 & 0 & 0 & 2 & 2 \\
\hline O'ahu & $\mathrm{OA}$ & $2002-2017$ & 20 & 4 & 0 & 4 & 8 \\
\hline O'ahu & $\mathrm{OB}$ & $2002-2018$ & 201 & 10 & 0 & 161 & 171 \\
\hline Maui Nui & MA & $2004-2018$ & 51 & 1 & 2 & 16 & 19 \\
\hline Maui Nui & $\mathrm{MB}$ & $2000-2018$ & 140 & 60 & 118 & 118 & 296 \\
\hline Maui Nui & OB & $2007-2017$ & 3 & 1 & 0 & 1 & 2 \\
\hline Hawai'i & $\mathrm{HA}$ & $2002-2018$ & 117 & 86 & 0 & 20 & 106 \\
\hline Hawai'i & $\mathrm{HB}$ & $2003-2015$ & 37 & 12 & 0 & 2 & 14 \\
\hline Total & & & 767 & 279 & 120 & 350 & 749 \\
\hline
\end{tabular}

This is the second abundance estimate for stocks of bottlenose dolphins in the main Hawaiian Islands, and the first attempt to understand temporal trends in population sizes of these stocks. The dataset used for these estimates builds upon the dataset used for the abundance estimates published in 2009 (Baird et al. 2009). For the period before 2006, our POPAN abundance estimates roughly correlate with the original estimates published in Baird et al. (2009), calculated using a closed Lincoln-Petersen model, with the exception of the O'ahu stock. In that stock, our abundance estimates are considerably lower than those of Baird et al. (2009). In that study, the authors indicated that estimates from the O'ahu stock may be inflated due to (1) low individual sample size, (2) small number of encounters, (3) small number of sample years included in the study, and therefore (4) small number of resights, although the 2009 study also took into consideration the possibility that some of the sampled groups came from an offshore stock (Baird et al. 2009). Adding additional years to the study and increasing the number of resights has decreased abundance estimates in early years. In the remaining 3 stocks, the estimates from this study concur with those from the 2009 study, albeit based on largely overlapping datasets.

Bottlenose dolphins inhabit the protected, shallow, nearshore waters off the main Hawaiian Islands, and as such they regularly interact with humans using the same areas for a variety of activities, including dolphin-watching tourism, fishing, recreational boating, shipping, and naval activities. These activities increase cumulative noise interference, resource com- petition, and risk of injury or death for all species that rely primarily upon the same habitat. They must also contend with habitat degradation and contaminant loading generated by the large coastal populations living on the islands, and face an elevated risk of ingestion or entanglement in marine debris, especially plastics from land-based activities (Currie et al. 2017). Relatively little is known about the effects of these activities on stocks of bottlenose dolphins specifically, but they likely face threats similar to better studied highly mobile marine species, such as other odontocetes, sea turtles, and monk seals. From these studies, major risk factors include exposure to pathogens (both natural and anthropogenic) and contaminants (e.g. Littnan et al. 2006, Lopez et al. 2012, Bachman et al. 2014, Barbieri et al. 2018, Kratofil et al. 2020), and interactions between the 2 factors (Aguirre et al. 1994), as well as trauma related to fishing gear and boat strikes (e.g. Chaloupka et al. 2008, McCracken 2010, Baird 2016). These effects may vary spatially according to individual or group-specific variability in ranging behavior, so that the cumulative impact to an individual is highly dependent on its spatial use (Baird 2016). For example, bottlenose dolphins inhabiting the leeward waters of Hawai'i Island are likely to be heavily impacted by recreational vessels and fishing, while the O'ahu stock is likely heavily impacted by noise from shipping activity (Baird 2016), and the Kaua'i/Ni'ihau stock overlaps spatially with naval activities to the northwest of Kaua'i (Baird et al. 2017). The impact of these activities on nearshore stocks of dolphins and whales is unknown; the present study indicates a 


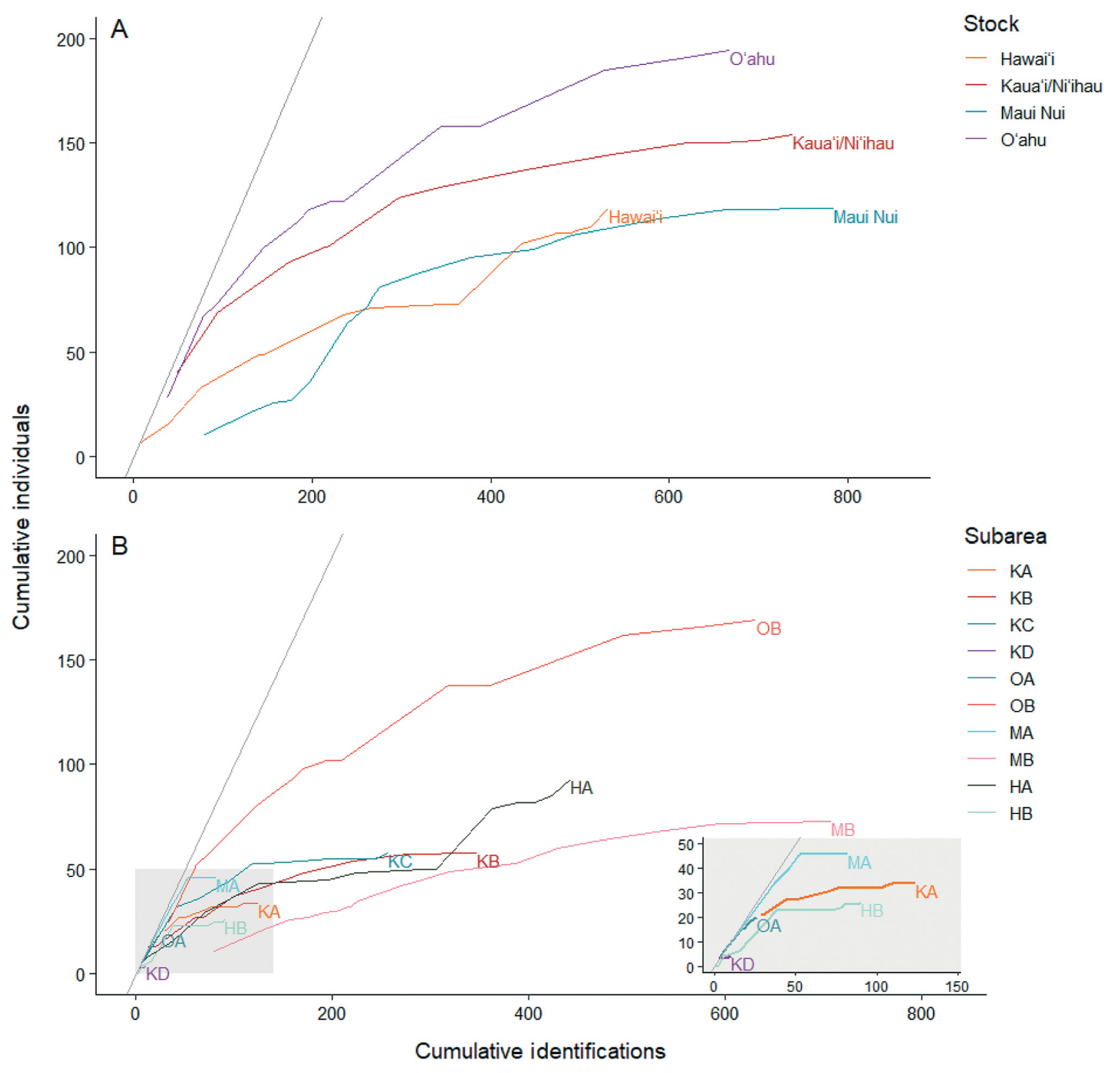

Fig. 4. Discovery curves illustrating sampling coverage based on the rate of accumulation of new individual Hawaiian bottlenose common dolphins over cumulative number of sightings, both (A) by stock and (B) by subarea within each stock. In (B), the lower left plot region is enlarged in grey (lower right). In each plot, a 1:1 line is shown in grey as a reference. Subarea designations in (B) are as follows: Kaua'i/Ni'ihau: KA, KB, KC, KD; O'ahu: OA, OB; Maui Nui: MA, MB; Hawai'i: HA, HB. Geographic locations of each subarea are shown in Fig. 3A

possible long-term negative trend in abundance across the main Hawaiian Island meta-population of bottlenose dolphins $(95 \% \mathrm{CI}$ of slope of population growth: -19.3 to -4.8 ), which may be correlated with nearshore habitat degradation by anthropogenic activities.

Abundance estimates for all stocks in this study range from the 10s to low 100s, with confidence intervals indicating that some stocks may have an abundance of up to 400 individuals. This relatively low abundance has been documented in stocks of bottlenose dolphins off multiple remote islands or archipelagos (e.g. Silva et al. 2009, Milmann et al. 2017, Estrade \& Dulau 2020), which act as productive hotspots in otherwise oligotrophic areas of the ocean, as well as some less remote islands (Brereton et al. 2018). Population sizes of approximately 100 individuals are relatively common among stocks of bottlenose dolphins with well-defined, restricted ranges and a high 
Table 2. Model Akaike's information criterion corrected for small sample size ( $\left.\mathrm{AIC}_{\mathrm{c}}\right)$ and weight from the models with weight $>0.0001$ within each island stock of Hawaiian bottlenose common dolphins. p (capture probability) and $\beta$ (probability of entry) for each model are shown in the first 2 columns. Lowest $\mathrm{AIC}_{\mathrm{c}}$ indicates the optimal model, but all models were averaged by their weight to account for model uncertainty. Because all models were corrected for overdispersion $(\hat{c}>1), \mathrm{AIC}_{\mathrm{c}}, \mathrm{Delta} \mathrm{AIC}_{\mathrm{c} r}$ and deviance are quasi-estimates. npar: number of parameters

\begin{tabular}{|c|c|c|c|c|c|c|c|c|}
\hline $\mathrm{p}$ & $\beta$ & npar & $\mathrm{AIC}_{\mathrm{c}}$ & Delta $\mathrm{AIC}_{\mathrm{c}}$ & Weight & Deviance & Stock & $\hat{C}$ \\
\hline$\sim$ Subarea $\times$ Time & -Subarea & 61 & 1321 & 0.0 & 0.9969 & 61.9 & Kaua'i/Ni'ihau & 1.1 \\
\hline$\sim$ Subarea $\times$ Time & $\sim 1$ & 58 & 1333 & 11.5 & 0.0031 & 81.1 & Kaua'i/Ni'ihau & 1.1 \\
\hline Time & $\sim$ Subarea & 21 & 651 & 0.0 & 0.7870 & -201.3 & O’ahu & 1.7 \\
\hline$\sim$ Time & $\sim 1$ & 20 & 654 & 3.1 & 0.1636 & -195.9 & O'ahu & 1.7 \\
\hline$\sim$ Subarea $\times$ Time & $\sim 1$ & 36 & 657 & 6.1 & 0.0369 & -230.2 & O’ahu & 1.7 \\
\hline$\sim$ Subarea $\times$ Time & $\sim$ Subarea & 37 & 659 & 8.4 & 0.0120 & -230.4 & O’ahu & 1.7 \\
\hline Time & $\sim$ Time & 34 & 665 & 14.8 & 0.0005 & -216.6 & O'ahu & 1.7 \\
\hline$\sim$ Subarea $\times$ Time & Subarea & 41 & 1155 & 0.0 & 1.0000 & -26.1 & Maui Nui & 1.2 \\
\hline$\sim$ Time & $\sim$ Subarea $\times$ Time & 52 & 1047 & 0.0 & 0.9855 & 3.5 & Hawai`i & 1.1 \\
\hline$\sim$ Time & $\sim$ Subarea & 22 & 1056 & 8.9 & 0.0114 & 86.5 & Hawai'i & 1.1 \\
\hline$\sim$ Time & $\sim$ Time & 36 & 1059 & 12.4 & 0.0020 & 57.0 & Hawai'i & 1.1 \\
\hline$\sim$ Time & $\sim 1$ & 21 & 1061 & 13.7 & 0.0011 & 93.5 & Hawai'i & 1.1 \\
\hline
\end{tabular}

degree of site fidelity, in both island-associated and coastal habitats (Wilson et al. 1999, Ingram \& Rogan 2002, Silva et al. 2009). Based on a line-transect survey conducted in 2003, Barlow (2006) estimated approximately 465 individuals in the main Hawaiian Island meta-population, which may be equivalent to roughly 100-150 individuals per stock in 2003.

\subsection{Caveats to estimates of abundance and trends}

While there were negative trends in both the Kaua'i/Ni'ihau and O'ahu stocks, the annual estimates did not differ significantly throughout the study, so the trends cannot be considered reliable. Significant declines were found in the Maui Nui stock; however, the geographic range of sightings varied greatly on an annual basis and contracted over the study period in both the Maui Nui and O'ahu stocks (Figs. S2 \& S3) despite a dramatic increase in the number of encounters (primarily driven by citizen scientist contributions, see Fig. S1), which may have affected model estimates of annual abundance and apparent survival, as well as confidence intervals. The effect of this is apparent in the discovery curves (Fig. 4A,B), which show that the apparent flattening of the curve for each stock is driven primarily by sampling in 1 subarea, while the second subarea in each stock is truncated due to small sample size, and has an approximate relationship of 1:1. In both stocks, the number of individuals sighted annually did not change appreciably over the study period (Table 5), although the number of sightings increased dramatically in recent years, indicating a large number of resights of the same individuals. This is reflected in the increase in capture probability over time in both stocks (Table S1), and results in a smaller abundance estimate over time. A lack of associated effort data makes it unclear whether the increase in capture probability is due to resampling within a smaller portion of the range of the stock, or whether the stock has in fact decreased in abundance and range over time. Further, in the O'ahu stock, the optimal POPAN model considered only annual variance when estimating capture probability (Table 2), even though

Table 3. Model-averaged estimates and standard error (SE) of apparent survival $(\phi)$ within each Hawaiian bottlenose common dolphin stock

\begin{tabular}{|lcc|}
\hline Stock & Estimate & SE \\
\hline Kaua'i/Ni'ihau & 0.9 & 0.011 \\
O'ahu & 0.84 & 0.023 \\
Maui Nui & 0.86 & 0.013 \\
Hawai'i & 0.85 & 0.019 \\
\hline
\end{tabular}

Table 4. Mean and variance of the proportion of distinctive individuals $(\theta)$ in encounters within each Hawaiian bottlenose common dolphin stock, used to correct POPAN estimates of the abundance of distinctive animals based on the Delta method

\begin{tabular}{|lcc|}
\hline Stock & $\theta$ & $\theta_{\text {var }}$ \\
\hline Kaua'i/Ni'ihau & 0.74 & 0.0269 \\
O'ahu & 0.87 & 0.0045 \\
Maui Nui & 0.83 & 0.0044 \\
Hawai'i & 0.75 & 0.0265 \\
\hline
\end{tabular}




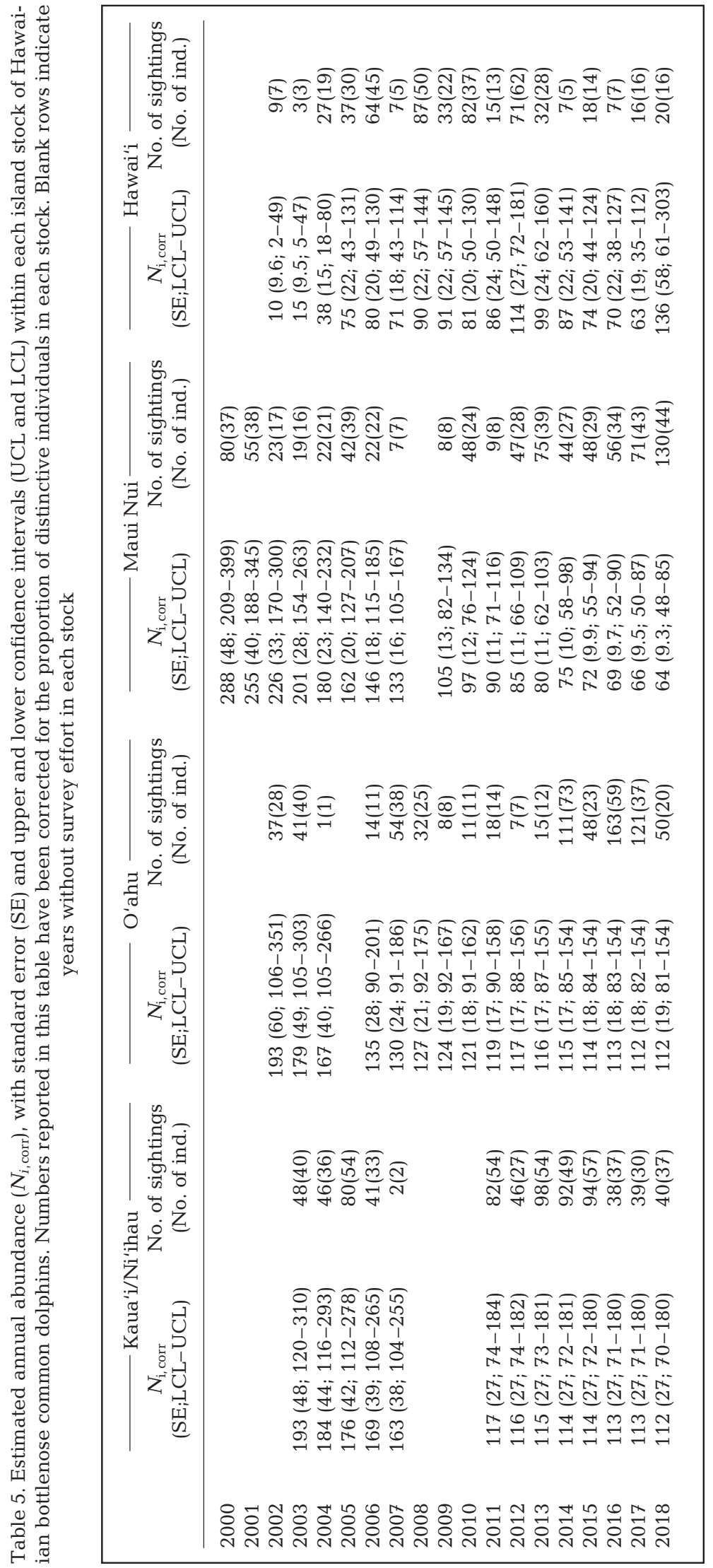

individual habitat use is significantly smaller than the entire range of the stock (Fig. 2), indicating that survey effort likely covered only a portion of the stock range. Contracted survey effort in these 2 stocks will affect model fit, so that these estimates may reflect only a portion of the total stock, especially in later years. Although survey effort was more consistent in the Kaua'i/ Ni'ihau stock, annual variability due to weather or funding constraints likely had a similar effect on model-estimated abundance and apparent survival.

Although confidence intervals were large for the Hawai'i stock, indicating that the population may not be growing at the rate estimated by the model, our estimate of $95 \%$ CIs for trend indicate that it is unlikely that the stock is declining. The mean annual growth of $10.5 \%$ in this stock is greater than the species' maximum expected growth rate of $4 \%$, and was driven primarily by the discovery of new individuals in the early part of the survey (20022007), as well as influxes of a relatively large number of new individuals in 2012 that may represent an immigration event, as most individuals were resighted later in the study.

Abundance estimates for the Hawai'i stock only considered observations made on the leeward side of the island due to a lack of observations from the windward side, and are likely underestimates of true stock abundance. On the windward side, 33 observations were made of 33 distinct individuals over the study period, 32 of which were obtained during a 2016 survey conducted by the Pacific Islands Fisheries Science Center. Of the 33 individuals, 7 were observed at least twice over the survey period, with 1 individual observed 3 times. Of those 7,4 were resighted in subarea HA, and 2 in subarea HB (see Fig. 3 for subarea locations). In order to conduct nonbiased assessments of abundance and trends on the windward side of Hawai'i Island, it will be necessary to increase survey effort in that region.

Survey effort was lower on the windward side of all islands compared to the leeward side; therefore, we suggest that regular surveys on the windward side of each of the Hawaiian Islands may increase abun- 
dance estimates for all stocks. However, increasing survey effort off the windward side of the islands, or increasing survey effort more generally to achieve a more consistent spatio-temporal sampling effort, is likely to inflate trend estimates going forward, due to the likelihood that increased spatial coverage will increase the number of individuals observed. Simulation studies will be necessary to understand the impact of increased sampling effort before comparing current abundance estimates with any future estimates based on increased survey effort.

An additional source of potential variability comes from the possibility for inclusion of individuals from the offshore stock or other potential island-associated stocks (e.g. from the Northwestern Hawaiian Islands), which could artificially inflate abundance estimates and increase confidence intervals around annual estimates. When offshore groups are seen only once, their inclusion in the dataset can artificially decrease estimated apparent survival rates and increase abundance estimates as well as the uncertainty around those estimates. While we consider all animals included in the study to be part of 1 of the 4 main Hawaiian Island stocks based on their sighting location and size, network analysis of long-term photo-ID datasets have revealed that some individuals are not socially connected with the resident populations. Overall, $15.42 \%(n=128)$ of individuals in the dataset are not associated with main Hawaiian Island social networks (Cascadia Research Collective unpublished data), mostly in the O'ahu and Maui Nui stocks. Of these, 118 individuals (97\%) were observed on a single occasion. This suggests the possibility for some influence from offshore groups that has not yet been accounted for, although social connectivity alone is not sufficient to determine which individuals are not part of a stock. Alternatively, in the O'ahu and Maui Nui stocks in particular, this pattern may indicate additional population structure that has not yet been described. As above, consistent annual to semi-annual sampling would improve the ability to identify and remove any offshore individuals, thus reducing uncertainty in estimates of apparent survival, abundance, and annual trends.

\subsection{Bottlenose dolphins exhibit habitat preferences within stocks}

Often, coastal areas are co-inhabited by resident and transient populations of bottlenose dolphins, which can confound mark-recapture abundance estimates by violating the assumption that marked animals do not emigrate (e.g. Silva et al. 2009, Conn et al. 2011), which can negatively bias apparent survival (Pradel et al. 1997). In our case, only a small proportion of marked individuals were determined not to be part of 1 of the 4 Hawaiian stocks, and these were removed from the study before model fitting.

Rather, we found that individuals tended to have a smaller home range than the entire available habitat within each stock, indicating strong site fidelity within populations. The strongest spatial heterogeneity in individual habitat use was found in Maui Nui, where individual interannual movements were as much as $10 \mathrm{~km}(>30 \%)$ less than would be expected in a randomly mixing stock (Fig. 2), and the second largest difference was found off Hawai'i Island. However, data from 1 bottlenose dolphin satellite tagged off Kaua'i over a period of $34 \mathrm{~d}$ shows that movements over a large proportion of the stock range are possible in a relatively short period of time (Baird et al. 2012).

Spatial heterogeneity in individual habitat use, as well as variability in individual degree of residency, is common in bottlenose dolphin populations and has been exhibited at various scales within stocks (e.g. Forcada et al. 2004, Haughey et al. 2020). While this pattern of restricted habitat use has been observed in other island-associated bottlenose dolphin populations (e.g. Milmann et al. 2017), other studies have found that some individuals will emigrate temporarily, returning to the island after multiple months (e.g. Silva et al. 2009, Dinis et al. 2016, Estrade \& Dulau 2020), indicating that the island may be part of a larger habitat range. It is possible that individual movement, residency patterns, or habitat preferences are another learned behavior in this species, which has been shown to learn various other kinds of behaviors (e.g. Reiss \& McCowan 1993, McCowan et al. 2000, Krützen et al. 2005, 2014, Sargeant et al. 2005); social learning of these behaviors would contribute to the spatial heterogeneity observed within stocks in this study.

This heterogeneity in habitat use, combined with annual variability in survey effort, is likely to negatively bias apparent survival estimates. Weatherdriven or funding-related variability in spatial coverage within stock boundaries led to a disproportionate number of individuals encountered once during the course of the study. Because the POPAN formulation of the Jolly-Seber mark-recapture model does not distinguish between permanent emigration and death, a large number of individuals seen only once will artificially inflate model estimates of emigration/ death and decrease apparent survival in each stock 


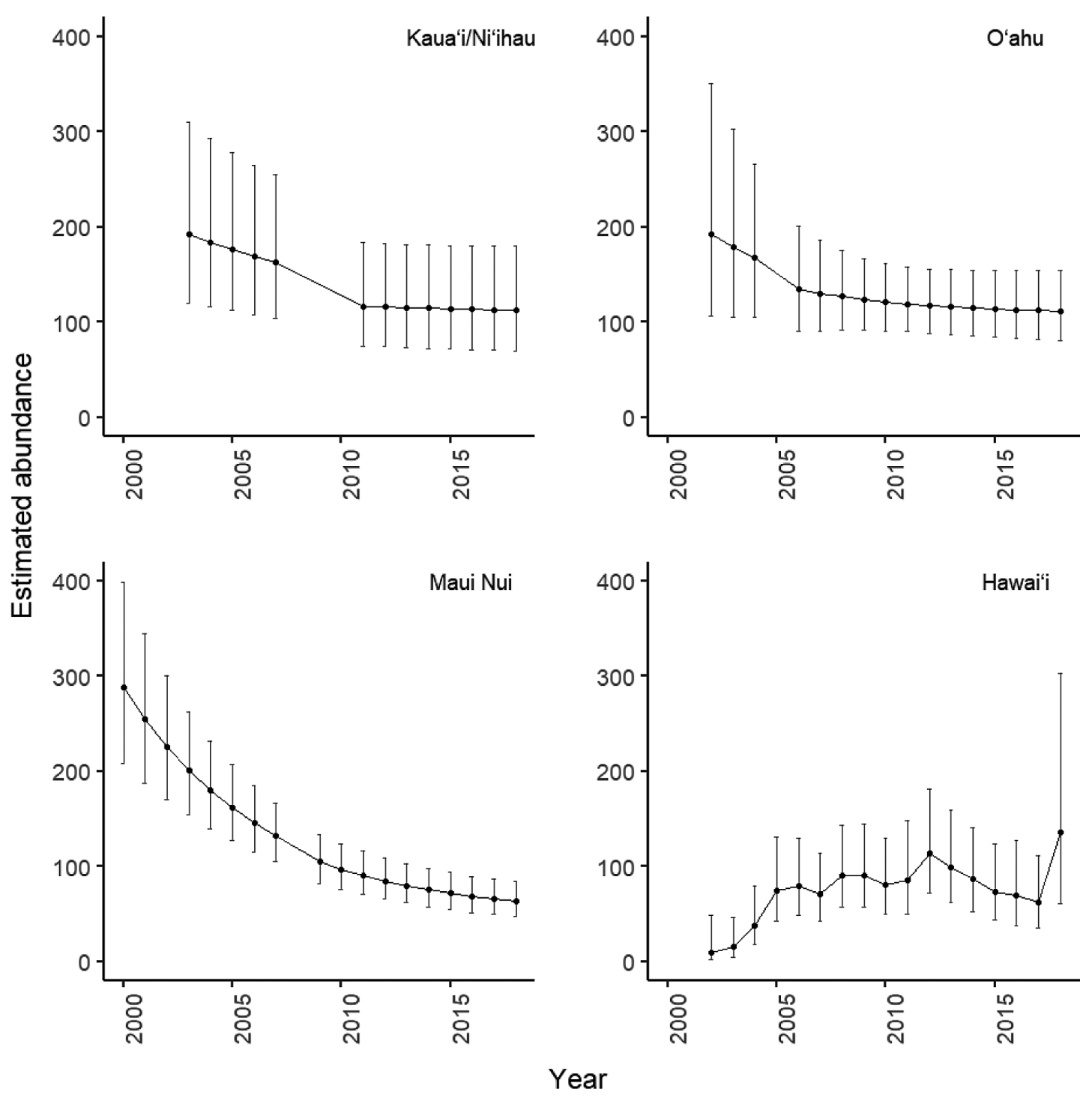

Fig. 5. Population trends for each of the 4 island stocks within the Hawaiian Island population of bottlenose dolphins. Vertical bars indicate $95 \%$ confidence intervals. Abundance estimates are only shown for years in which there were encounters within each island stock

(Pradel et al. 1997); this is the effect of transient populations, but can also cause bias if a region within the study area is sampled only once or a few times. Low apparent survival estimates in all stocks in this study are likely driven at least in part by non-random sampling, and offset by allowing the probability of entry to vary by subarea. Subdividing stocks into subareas helped identify subareas that are well sampled, and others where additional sampling would improve model estimates of abundance and apparent survival. Because POPAN assumptions of homogeneous capture probability, independent probability of capture, and constant sample area are sensitive to annual heterogeneity in survey design and individual habitat use, it is likely that continued effort in poorly sampled regions would improve estimates of apparent survival, as well as decrease confidence intervals in future estimates of annual abundance.

\subsection{Consistent sampling is important to understanding population trends}

These abundance estimates were possible due to approximately annual surveys of each stock since 2000 , as well as the invaluable contributions of citizen scientists. Without this survey effort in the near- 
shore Hawaiian Island habitat, it would not have been possible to assess trends in the population demographics of the 4 stocks in the region. Within each stock, the total number of encounters was significantly increased by the efforts of citizen scientists and research organizations collaborating with CRC and PWF by sharing ID photos of their encounters. In Maui Nui and O'ahu, these efforts increased the geographic range of the sampling area to include islands unsurveyed by CRC and PWF. Our understanding of the O'ahu stock is largely driven by citizen scientist contributions, which make up the bulk of our observations from this region.

However, logistical constraints to that effort, most notably due to funding and weather (including a leeward sampling bias due to consistent high winds on the windward side of each island), affect geographic coverage within stocks from year to year. This variability in effort introduces uncertainty into estimates of demographic parameters such as abundance and trends in abundance over time. For example, the large annual variation in capture probability among subareas in this study likely reflects differences in survey effort in each year, although this correlation cannot be tested directly because effort data are not available from all citizen scientist survey effort, and because CRC surveys were not restricted to bottlenose dolphins or the nearshore habitat. Managers should take uncertainty due to logistical constraints on survey effort into consideration when using the present study to inform stock assessments or management plans, and future work should aim to include consistent sampling of the entire bottlenose dolphin habitat within all 4 stocks on an annual to semi-annual basis (defined in Fig. 3A).

\subsection{Management considerations}

The estimates of bottlenose dolphin abundance presented here, based on the best data currently available, indicate a strong likelihood that 3 out of 4 bottlenose dolphin stocks in the Hawaiian Islands are currently in decline. To date, very little is known about the health and ecology of these populations; updated abundance estimates and population trends are therefore important information when managing these stocks. Although there are biases to the study design that most likely affected these estimates, a conservative approach to management will incorporate these estimates and trends into their management plans as the best available data. Concurrently, managers should look to secure funding directed specifically at addressing the biases described here, so that future management plans may be based on data with a higher degree of confidence. Similarly, studies examining the potential drivers of declines, especially in the 2 stocks with higher levels of confidence, will be an important step toward the management and conservation of bottlenose dolphins in the Hawaiian Islands.

Acknowledgements. We thank the many citizen scientists who have contributed photos to $\mathrm{CRC}$ to make this project possible, as well as the members of CRC's field team and volunteers who have worked on this project since 2000. We also thank the many field team members and both the staff and volunteers at the PWF who contributed to this project over the years. Paul Johnson, Dan McSweeney, the Hawaiian Island Humpback Whale National Marine Sanctuary, NMFS Pacific Island Fisheries Science Center, Mark Deakos, and Chuck Babbitt all made between 50 and 100 contributions to this study. Field efforts were funded by grants and contracts from NMFS (Southwest Fisheries Science Center, Pacific Islands Fisheries Science Center, Protected Resources Program, Bycatch Reduction Engineering Program), the US Navy (Office of Naval Research, Living Marine Resources, Pacific Fleet), the Wild Whale Research Foundation, and the Tides Foundation, as well as members and supporters of PWF. Research was undertaken under permit numbers 7311509, 731-1774, 15330 and 20605 issued to R.W.B. and LOC 13427 and 18101 issued to PWF. Photo-ID matching was assisted by a number of CRC and PWF interns and volunteers. We thank Jeff Laake, Alex Curtis, Amanda Bradford, Jim Carretta, and Tomo Eguchi for their valuable input on the analysis of the present dataset, as well as 2 anonymous reviewers of the manuscript.

\section{LITERATURE CITED}

Aguirre AA, Balazs GH, Zimmerman B, Galey FD (1994) Organic contaminants and trace metals in the tissues of green turtles (Chelonia mydas) afflicted with fibropapillomas in the Hawaiian Islands. Mar Pollut Bull 28:109-114

Akaike H (1998) Information theory and an extension of the maximum likelihood principle. In: Parzen E, Tanabe $\mathrm{K}$, Kitagawa G (eds) Selected papers of Hirotugu Akaike. Springer Series in Statistics (Perspectives in Statistics). Springer New York, New York, NY, p 199-213

Anderson DR, Burnham KP, White GC (1994) AIC model selection in overdispersed capture-recapture data. Ecology 75:1780-1793

Bachman MJ, Keller JM, West KL, Jensen BA (2014) Persistent organic pollutant concentrations in blubber of 16 species of cetaceans stranded in the Pacific Islands from 1997 through 2011. Sci Total Environ 488-489:115-123

Baird RW (2016) The lives of Hawai'i's dolphins and whales: natural history and conservation. University of Hawai'i Press, Honolulu, HI

* Baird RW, Gorgone AM, McSweeney DJ, Ligon AD and others (2009) Population structure of island-associated dolphins: evidence from photo-identification of common bottlenose dolphins (Tursiops truncatus) in the main Hawaiian Islands. Mar Mamm Sci 25:251-274 
Baird RW, Webster DL, Schorr GS, Aschettino JM, Gorgone AM, Mahaffy SD (2012) Movements and spatial use of odontocetes in the western main Hawaiian Islands: results from satellite tagging and photo-identification of Kaua'i and Ni'ihau in July/August 2011. Annual progress report under Grant No. N00244-10-1-0048 from the Naval Postgraduate School. https://www.cascadiaresearch.org/ files/Projects/Hawaii/BairdetalNPS2012_0.pdf

* Baird RW, Webster DL, Aschettino JM, Schorr GS, McSweeney DJ (2013) Odontocete cetaceans around the main Hawaiian Islands: habitat use and relative abundance from small-boat sighting surveys. Aquat Mamm 39:253-269

Baird RW, Webster DL, Morrissey R, Rone BK and others (2017) Odontocete studies on the Pacific Missile Range Facility in February 2016: satellite-tagging, photo-identification, and passive acoustic monitoring. Final Report. Prepared for Commander, Pacific Fleet, Environmental Readiness Division, Pearl Harbor, HI. Submitted to Naval Facilities Engineering Command (NAVFAC) Pacific, EV2 Environmental Planning, Pearl Harbor, HI, under Contract No. N62470-15-D-8006 Task Order KB0 issued to HDR Inc., Honolulu, HI, June 2017. https://www.cascadiaresearch. org/publications

Barbieri M, Duncan C, Harting AL, Pabilonia KL and others (2018) Survey for placental disease and reproductive pathogens in the endangered Hawaiian monk seal (Neomonachus schauinslandi). J Wildl Dis 54:564-568

Barlow J (2006) Cetacean abundance in Hawaiian waters estimated from a summer/fall survey in 2002. Mar Mamm Sci 22:446-464

* Bejder L, Samuels A, Whitehead H, Gales N and others (2006) Decline in relative abundance of bottlenose dolphins exposed to long-term disturbance. Conserv Biol 20:1791-1798

Bezamat C, Simões-Lopes PC, Castilho PV, Daura-Jorge FG (2019) The influence of cooperative foraging with fishermen on the dynamics of a bottlenose dolphin population. Mar Mamm Sci 35:825-842

Bradford AL, Forney KA, Oleson EM, Barlow J (2017) Abundance estimates of cetaceans from a line-transect survey within the US Hawaiian Islands Exclusive Economic Zone. Fish Bull 115:129-142

Bradford AL, Baird RW, Mahaffy SD, Gorgone AM and others (2018) Abundance estimates for management of endangered false killer whales in the main Hawaiian Islands. Endang Species Res 36:297-313

Brereton T, Jones D, Leeves K, Lewis K, Davies R, Russel T (2018) Population structure, mobility and conservation of common bottlenose dolphin off south-west England from photo-identification studies. J Mar Biol Assoc UK 98: 1055-1063

Buckstaff KC (2004) Effects of watercraft noise on the acoustic behavior of bottlenose dolphins, Tursiops truncatus, in Sarasota bay, Florida. Mar Mamm Sci 20:709-725

Burnham KP (1987) Design and analysis methods for fish survival experiments based on release-recapture. American Fisheries Society, Bethesda, MD

Carretta JV, Danil K, Chivers SJ, Weller DW and others (2016) Recovery rates of bottlenose dolphin (Tursiops truncatus) carcasses estimated from stranding and survival rate data. Mar Mamm Sci 32:349-362

Carretta JV, Forney KA, Oleson EM, Weller DW and others (2019) US Pacific marine mammal stock assessments: 2018. NOAA Tech Memo NMFS-SWFSC-617
Chaloupka M, Work TM, Balazs GH, Murakawa SK, Morris R (2008) Cause-specific temporal and spatial trends in green sea turtle strandings in the Hawaiian Archipelago (1982-2003). Mar Biol 154:887-898

Conn PB, Gorgone AM, Jugovich AR, Byrd BL, Hansen LJ (2011) Accounting for transients when estimating abundance of bottlenose dolphins in Choctawhatchee Bay, Florida. J Wildl Manag 75:569-579

* Connor RC, Heithaus MR, Barre LM (2001) Complex social structure, alliance stability and mating access in a bottlenose dolphin 'super-alliance'. Proc R Soc B 268: 263-267

Currie JJ, Stack SH, McCordic JA, Kaufman GD (2017) Quantifying the risk that marine debris poses to cetaceans in coastal waters of the 4-island region of Maui. Mar Pollut Bull 121:69-77

* Dinis A, Alves F, Nicolau C, Ribeiro C, Kaufmann M, Cañadas A, Freitas L (2016) Bottlenose dolphin Tursiops truncatus group dynamics, site fidelity, residency and movement patterns in the Madeira Archipelago (NorthEast Atlantic). Afr J Mar Sci 38:151-160

Dwyer SL, Kozmian-Ledward L, Stockin KA (2014) Shortterm survival of severe propeller strike injuries and observations on wound progression in a bottlenose dolphin. N Z J Mar Freshw Res 48:294-302

Estrade V, Dulau V (2020) Abundance and site fidelity of bottlenose dolphins off a remote oceanic island (Reunion Island, southwest Indian Ocean). Mar Mamm Sci 36: 871-896

F Forcada J, Gazo M, Aguilar A, Gonzalvo J, Fernández-Contreras M (2004) Bottlenose dolphin abundance in the NW Mediterranean: addressing heterogeneity in distribution. Mar Ecol Prog Ser 275:275-287

* Haughey R, Hunt T, Hanf D, Rankin RW, Parra GJ (2020) Photographic capture-recapture analysis reveals a large population of Indo-Pacific bottlenose dolphins (Tursiops aduncus) with low site fidelity off the North West Cape, Western Australia. Front Mar Sci 6:781

*Hurvich CM, Tsai CL (1989) Regression and time series model selection in small samples. Biometrika 76:297-307

* Ingram SN, Rogan E (2002) Identifying critical areas and habitat preferences of bottlenose dolphins Tursiops truncatus. Mar Ecol Prog Ser 244:247-255

Jolly GM (1965) Explicit estimates from capture-recapture data with both death and immigration-stochastic model. Biometrika 52:225-248

Karczmarski L, Huang SL, Wong WH, Chang WL, Chan SC, Keith M (2017) Distribution of a coastal delphinid under the impact of long-term habitat loss: Indo-Pacific humpback dolphins off Taiwan's west coast. Estuaries Coasts 40:594-603

Kery M, Schaub M (2012) Bayesian population analysis using WinBUGS, Elsevier, Amsterdam

Kratofil MA, Ylitalo GM, Mahaffy SD, West KL, Baird RW (2020) Life history and social structure as drivers of persistent organic pollutant levels and stable isotopes in Hawaiian false killer whales (Pseudorca crassidens). Sci Total Environ 733:138880

Krützen M, Mann J, Heithaus MR, Connor RC, Bejder L, Sherwin WB (2005) Cultural transmission of tool use in bottlenose dolphins. Proc Natl Acad Sci USA 102: 8939-8943

Krützen M, Kreicker S, MacLeod CD, Learmonth J, Kopps AM, Walsham P, Allen SJ (2014) Cultural transmission of tool use by Indo-Pacific bottlenose dolphins (Tursiops sp.) 
provides access to a novel foraging niche. Proc R Soc B 281:20140374

Laake J (2014) RMark: an R Interface for analysis of capturerecapture data with MARK. Alaska Fisheries Science Center, NOAA, NMFS. http://www.afsc.noaa.gov/ Publications/ProcRpt/PR2013-01.pdf

Lebreton JD, Burnham KP, Clobert J, Anderson DR (1992) Modeling survival and testing biological hypotheses using marked animals: a unified approach with case studies. Ecol Monogr 62:67-118

Littnan CL, Stewart BS, Yochem PK, Braun R (2006) Survey for selected pathogens and evaluation of disease risk factors for endangered Hawaiian monk seals in the main Hawaiian Islands. EcoHealth 3:232-244

* Lopez J, Boyd D, Ylitalo GM, Littnan C, Pearce R (2012) Persistent organic pollutants in the endangered Hawaiian monk seal (Monachus schauinslandi) from the main Hawaiian Islands. Mar Pollut Bull 64:2588-2598

Louis M, Simon-Bouhet B, Viricel A, Lucas T, Gally F, Cherel Y, Guinet C (2018) Evaluating the influence of ecology, sex and kinship on the social structure of resident coastal bottlenose dolphins. Mar Biol 165:80

Martien KK, Baird RW, Hedrick NM, Gorgone AM and others (2012) Population structure of island-associated dolphins: evidence from mitochondrial and microsatellite markers for common bottlenose dolphins (Tursiops truncatus) around the main Hawaiian Islands. Mar Mamm Sci 28:E208-E232

Maxwell SM, Hazen EL, Bograd SJ, Halpern BS and others (2013) Cumulative human impacts on marine predators. Nat Commun 4:2688

McCowan B, Marino L, Vance E, Walke L, Reiss D (2000) Bubble ring play of bottlenose dolphins (Tursiops truncatus): implications for cognition. J Comp Psychol 114:98-106

* McCracken ML (2010) Adjustments to false killer whale and short-finned pilot whale bycatch estimates. PIFSC Working Paper WP-10-007. https://repository.library.noaa.gov/ view/noaa/15661

* Milmann LC, Danilewicz D, Baumgarten J, Ott PH (2017) Temporal-spatial distribution of an island-based offshore population of common bottlenose dolphins (Tursiops truncatus) in the equatorial Atlantic. Mar Mamm Sci 33:496-519

Morteo E, Rocha-Olivares A, Arceo-Briseño P, Abarca-Arenas LG (2012) Spatial analyses of bottlenose dolphinfisheries interactions reveal human avoidance off a productive lagoon in the western Gulf of Mexico. J Mar Biol Assoc UK 92:1893-1900

O'Brien S, Robert B, Tiandry H (2005) Consequences of violating the recapture duration assumption of mark-recapture models: a test using simulated and empirical data from an endangered tortoise population. J Appl Ecol 42: 1096-1104

Pradel R, Hines JE, Lebreton JD, Nichols JD (1997) Capture-recapture survival models taking account of transients. Biometrics 53:60-72

R Core Team (2016) R: a language and environment for statistical computing. R Foundation for Statistical Computing, Vienna

Reif JS, Mazzoil MS, McCulloch SD, Varela RA, Goldstein JD, Fair PA, Bossart GD (2006) Lobomycosis in Atlantic

Editorial responsibility: Helene Marsh,

Townsville, Queensland, Australia

Reviewed by: 2 anonymous referees bottlenose dolphins from the Indian River Lagoon, Florida. J Am Vet Med Assoc 228:104-108

Reiss D, McCowan B (1993) Spontaneous vocal mimicry and production by bottlenose dolphins (Tursiops truncatus): evidence for vocal learning. J Comp Psychol 107:301-312

* Rogers CA, Brunnick BJ, Herzing DL, Baldwin JD (2004) The social structure of bottlenose dolphins, Tursiops truncatus, in the Bahamas. Mar Mamm Sci 20:688-708

Rosel PE, Mullin KD, Garrison L, Schwacke L and others (2011) Photo-identification capture-mark-recapture techniques for estimating abundance of bay, sound and estuary populations of bottlenose dolphins along the US east coast and Gulf of Mexico: a workshop report. NOAA Tech Memo NMFS-SEFSC-621

* Sargeant BL, Mann J, Berggren P, Krützen M (2005) Specialization and development of beach hunting, a rare foraging behavior, by wild bottlenose dolphins (Tursiops sp.). Can J Zool 83:1400-1410

Schwarz CJ, Arnason AN (1996) A general methodology for the analysis of capture-recapture experiments in open populations. Biometrics 52:860-873

Seber GAF (1965) A note on the multiple-recapture census. Biometrika 52:249-260

Seber G (1982) The estimation of animal abundance and related parameters. Macmillan, New York, NY

* Silva MA, Magalhães S, Prieto R, Santos RS, Hammond PS (2009) Estimating survival and abundance in a bottlenose dolphin population taking into account transience and temporary emigration. Mar Ecol Prog Ser 392: 263-276

Stolen MK, Barlow J (2003) A model life table for bottlenose dolphins (Tursiops truncatus) from the Indian River Lagoon system, Florida, USA Mar Mamm Sci 19: 630-649

* Switzer PV (1993) Site fidelity in predictable and unpredictable habitats. Evol Ecol 7:533-555

* Twiner MJ, Flewelling LJ, Fire SE, Bowen-Stevens SR and others (2012) Comparative analysis of three brevetoxinassociated bottlenose dolphin (Tursiops truncatus) mortality events in the Florida panhandle region (USA). PLOS ONE $7: \mathrm{e} 42974$

Wells RS, Scott MD (2018) Bottlenose dolphin, Tursiops truncatus, common bottlenose dolphin. In: Würsig B, Thewissen JGM, Kovacs K (eds) Encyclopedia of marine mammals, $3^{\text {rd }}$ edn. Academic Press, Cambridge, MA, p 118-125

* Wells RS, Rhinehart HL, Hansen LJ, Sweeney JC and others (2004) Bottlenose dolphins as marine ecosystem sentinels: developing a health monitoring system. EcoHealth $1: 246-254$

Wells RS, Natoli A, Braulik G (2019) Common bottlenose dolphin Tursiops truncatus (errata version published in 2019). The IUCN Red List of Threatened Species 2019: e.T22563A156932432. https://dx.doi.org/10.2305/IUCN. UK.2019-1.RLTS.T22563A156932432.en

*White GC, Burnham KP (1999) Program MARK: survival estimation from populations of marked animals. Bird Study 46:S120-S139

*Wilson B, Hammond PS, Thompson PM (1999) Estimating size and assessing trends in a coastal bottlenose dolphin population. Ecol Appl 9:288-300

Submitted: August 17, 2020

Accepted: February 3, 2021

Proofs received from author(s): April 29, 2021 